\title{
Quantification of dwarfing effect of different rootstocks in 'Picual' olive cultivar using UAV-photogrammetry
}

\author{
Jorge Torres-Sánchez ${ }^{1}$ (D) Raúl de la Rosa ${ }^{2}$ (D) - Lorenzo León ${ }^{2}$ (D) \\ Francisco M. Jiménez-Brenes ${ }^{1}$ (D) . Amal Kharrat ${ }^{2} \cdot$ Francisca López-Granados $^{1}$ (D)
}

Accepted: 13 July 2021 / Published online: 31 August 2021

(c) The Author(s) 2021

\begin{abstract}
Hedgerow orchard is an olive growing system where trees are planted at a super high-density higher than 20-fold (i.e., 1200-2500 trees $\mathrm{ha}^{-1}$ ) compared to the traditional density of olive orchards (usually 50 to 160 trees $\mathrm{ha}^{-1}$ ). It is dominating a great proportion of new plantations because harvesting can be fully mechanized, it is early bearing and has a relatively constant high productivity. However, there are a limited number of cultivars with sufficiently low vigour to be suitable for such plantation densities. For that reason, a set of low vigour cultivars and breeding selections has been used in a field experiment as rootstocks for reducing the vigour of "Picual", the most frequent cultivar planted in Spain. Tree vigour was characterized by measuring crown height, projected and side areas, and volume through the analysis of photogrammetric point clouds created from images acquired with an unmanned aerial vehicle. A significant reduction of the 'Picual' vigour was observed in most of the rootstocks tested, with canopy volume reduced up to one half. High variability on vigour, first harvesting and their relative relationship was observed between the different rootstocks used. This indicates there might be enough genetic variability to perform breeding selection for dwarfing rootstocks on 'Picual' olive cultivar.
\end{abstract}

Keywords Olive breeding $\cdot$ Drone $\cdot$ Hedgerow orchard $\cdot$ Tree vigour $\cdot 3 \mathrm{D}$ point cloud

\section{Introduction}

Olive (Olea europaea L.) is the most widespread tree fruit planted in the Mediterranean basin. Out of 10.6 Mha cultivated worldwide, $24.60 \%, 15.19 \%$ and $10.77 \%$ are in Spain, Tunisia and Italy, respectively (FAOSTAT, 2021). Hedgerow orchard is a recent olive

Jorge Torres-Sánchez

jtorres@ias.csic.es

$\triangle$ Francisca López-Granados

flgranados@ias.csic.es

1 Grupo Imaping, Instituto de Agricultura Sostenible-CSIC, Avda. Menéndez Pidal, s/n, 14004 Córdoba, Spain

2 Instituto de Investigación y Formación Agraria y Pesquera (IFAPA), Centro Alameda del Obispo, 14004 Córdoba, Spain 
growing system where trees are planted at much higher density (i.e., 1200-2500 trees $\mathrm{ha}^{-1}$ ) than the high-density (around 400 trees $\mathrm{ha}^{-1}$ ) or than traditional widely-spaced olive orchards (usually 50 to 160 trees $\mathrm{ha}^{-1}$ ). This intensive cropping system is nowadays being widely adopted not only in typical olive countries located in the Mediterranean Region, but also it is becoming the most common orchard design in new plantings in non-traditional production zones away from the Mediterranean Region, such as Argentina, Chile, Perú and Australia (Centeno et al., 2019; Connor et al., 2014; Torres et al., 2017). This is mainly due to advantages related to the fact that they are adapted to fully mechanized harvesting, easy disease and pest control, early bearing, and a relatively constant high productivity (Fernández-Escobar et al., 2013). However, the main drawback of this growing system is that super high-density planting leads to the need for low vigour cultivars with good productivity level; there is a scarcity of varieties with these characteristics. In Spain, 270 olive cultivars are available (Barranco \& Rallo, 2000; Barranco et al., 2000) and 'Arbequina' and 'Arbosana' varieties together with 'Koroneiki' to a minor extent are the only unique traditional cultivars that are really suitable for this hedgerow system (De la Rosa et al., 2007; Marino et al., 2017). Few attempts have been made to develop low vigour cultivars specifically adapted to this cropping system, such as 'Askal' in Israel (Lavee et al., 2003) or 'Sikitita' in Spain (Rallo et al., 2008). This shortage is mainly due to the high heterozygosity of this species, which produces a high variability on the breeding crosses making it difficult to find a genotype having all the desirable traits; and to the extended juvenile period of olives that makes the breeding selection process very long. These factors have hampered the obtaining of new cultivars through the combination of good adaptation to super-high density with other traits such as high oil quality or resistance to pests and diseases.

One of the most interesting cultivars to be adapted for hedgerows could be 'Picual', the most widely planted cultivar in Spain (University of Jaén, 2020). This is related to its high productivity, easiness of harvesting by trunk shakers (due to its low fruit removal force and large fruit size) and good adaptation to the environmental conditions. Besides, the oil composition of 'Picual', with high oleic acid and high phenol content is highly appreciated (León et al., 2011).So far, hedgerow field experiments including 'Picual' have not reported acceptable results because irrigation increases the tree volume, leading to the necessity of frequent pruning (Barranco et al., 2000). On the other hand, there are a wide range of traditional olive cultivars that, although not suitable for high-density orchards due to their high vigour, could have other characteristics such as high oil content or high oleic acid in oil that, together with their adaptation to different agroclimatic conditions, could make them very interesting for being used in breeding programs for hedgerow plantations (Navas-López et al., 2019, 2020). Therefore, looking for dwarfing rootstocks that could reduce the canopy vigour of some traditional cultivars, so that they could fit in to the modern hedgerow olive orchards, would be of great interest for this emerging olive growing system. This would permit having a wide range of olive cultivars able to be planted in hedgerow orchards and the ability to design multi-varietal orchards. This could have many advantages such as production of olive oils with a wide range of composition and organoleptic properties (Navas-López et al., 2020) and different sources of resistance to pests and diseases (Fernández-Escobar et al., 2013). Other advantages of the availability of a wider range of olive cultivars would be the possibility of combine pollinators and a higher efficiency in the use of machinery related to a potential lengthening of the harvest period.

In other fruit trees, especially apple, dwarfing rootstocks have been used for a very long time as a way to reduce tree canopy and vigour, and thus increase planting density (Lordan et al., 2018; Vyvyan, 1955). However, rootstocks have been scarcely used on olive trees due to the ease of self-rooting of this species (Warschefsky et al., 2016), although some 
rootstocks have been selected for Verticillium Wilt (Jiménez-Fernández et al., 2016) and frost (Pérez-López et al., 2008) resistance. Several attempts at selecting dwarfing rootstocks in olive have also been made as reviewed by Rugini and Pace (2016). This included a long-term evaluation of the vigour and productivity of 'Arbequina' when grafted in 18 different olive cultivars and trained in vase formation (Romero et al., 2014). However, their final suitability for hedgerow olive orchards has not yet been reported and, in any previous work, dwarfing rootstock has been used to increase the ability of traditional vigorous olive cultivars to be planted in high-density hedgerow orchards. Only one recent work has reported a high variability on the initial growth of 1 year old potted plants of 'Picual' when grafted with a collection of wild genotypes (Díaz-Rueda et al., 2020).

Evaluation of the dwarfing effect of the different rootstocks in breeding field experiments requires the measurement of the geometrical properties of every tree crown. Manual measurement of the plant properties is a laborious task especially in the case of the olive tree, whose crown has an irregular geometry (Rallo et al., 2020). To efficiently alleviate the hard manual work required in phenotyping experiments, different technologies have been used in recent years for the acquisition of 3D information (Paulus, 2019). Among the technological alternatives, one of those recently used is the generation of $3 \mathrm{D}$ point clouds representing the crops through the application of photogrammetric techniques to images acquired with an unmanned aerial vehicle (UAV). In these point clouds, each point provides a set of $\mathrm{X}, \mathrm{Y}, \mathrm{Z}$ coordinates representing the surface of the crop and the soil. UAV photogrammetry has been successfully used in phenotyping of herbaceous crops such as maize (Herrmann et al., 2020), sorghum (Watanabe et al., 2017) and rice (Kawamura et al., 2020), and of woody crops such as almond (López-Granados et al., 2019) and olive (León et al., 2017; Rallo et al., 2020). The usually large amount of points in the cloud generated through the use of these new technological tools in breeding experiments (e.g., 4782 points $\mathrm{m}^{-2}$, (de Castro et al., 2019)) requires robust and efficient analysis algorithms (Guijun et al., 2017; Perez-Sanz et al., 2017). The object based image analysis (OBIA) paradigm, based on the segmentation of images or point clouds, has been used in the creation of analysis algorithms of point clouds in phenotyping experiments in almond (Torres-Sánchez et al., 2018) and olive (de Castro et al., 2019).

In this context, the goal of the present work was to test the ability of a set of low vigour cultivars together with breeding selections as rootstocks in reducing the vigour of 'Picual' cultivar, and therefore, to increase the suitability of that cultivar for high-density hedgerow orchards. For that purpose, a UAV-photogrammetric point cloud and OBIA algorithm were used to quantify geometric parameters such as height, projected and transversal areas, and volume of every olive tree belonging to different rootstock-scion combinations to correctly select those able to induce a dwarfing effect on the 'Picual' cultivar. UAV data were compared to direct tree measurements at ground level in their ability to identify the dwarfing effect of the tested rootstocks.

\section{Materials and methods}

\section{Study site}

In 2015, one-year-old olive plants of eight seedlings of 'Sikitita' $\times$ 'Arbosana' cross of the olive breeding program of IFAPA-Alameda del Obispo-Córdoba (Spain), six 
Table 1 Plant material used in the study, including rootstocks for 'Picual' scion and 'Picual' on its own roots

Plant material grafted with Picual scion

\begin{tabular}{lll}
\hline Origin of the rootstock & Rootstock & $\begin{array}{l}\text { Number } \\
\text { of trees }\end{array}$ \\
\hline 'Sikitita' $\times$ 'Arbosana' & $77-36$ & 14 \\
& $78-5$ & 5 \\
& $78-6$ & 8 \\
& $82-2$ & 9 \\
Cultivars & $82-4$ & 10 \\
& $82-8$ & 7 \\
& $83-7$ & 14 \\
Wild olives & $90-5$ & 5 \\
& Arbequina & 18 \\
& Arbosana & 17 \\
& Sikitita & 18
\end{tabular}

Non-grafted Plant material

Cultivar

Number of trees

Picual (Picual-C) $)^{\mathrm{a}}$

${ }^{a}$ Letters have been added to Picual trees to distinguish between Picual grafted on Picual rootstock (PicualR) from Picual on its own roots (Picual-C)

cultivars and two wild olives (Table 1) were used as rootstocks for the 'Picual' cultivar. The eight seedlings were selected as coming from the cross of two low vigour cultivars suitable for high-density orchards (De la Rosa et al., 2007; Rallo et al., 2008). Four out of the six cultivars included are common for high-density orchards ('Arbequina', 'Arbosana', 'Sikitita', 'Tosca'), while the other is a high vigour cultivar ('Frantoio'). 'Picual' was also included in order to study the effect of self-grafting. The two wild rootstocks were included to test the effect on vigour of non-cultivated germplasm. Grafted plants were grown in the greenhouse together with additional 'Picual' plants on their own roots. All this plant material was used to set up a field comparative trial in April 2016. A randomized design with three blocks and with a number of plants per experimental plot, depending on plant availability, was set up. The trial was planted at a typical hedgerow density of $4 \times 1.5 \mathrm{~m}\left(1666\right.$ trees ha $\left.^{-1}\right)$ with $1000 \mathrm{~m}^{3} \mathrm{ha}^{-1}$ of yearly drip irrigation and located at the experimental farm of IFAPA $(37.853252 \mathrm{~N}, 4.805569 \mathrm{~W}$, WGS84) previously mentioned. Fertilization was applied to promote early growth of the plants to form the hedgerow and consisted of 40, 13 and 26 units per ha and year of nitrogen, phosphorous and potassium, respectively. The only frequent disease in the area of cultivation was peacock eye and preventive treatments with copper sulphate were 
applied three times a year. Plants were not pruned in order to evaluate the genetic effect of each rootstock and cultivar on the canopy volume.

\section{Field data acquisition and processing}

In April 2018, tree height and canopy volume were measured for each tree. Canopy volume was estimated based on the measurement of three canopy diameters including one vertical (V) and two horizontal (perpendicular) ones ( $\mathrm{H} 1$ and $\mathrm{H} 2)$ using the following formula:

$$
\text { Volume }=\frac{4}{3} \pi \frac{V * H 1 * H 2}{8}
$$

All fruits were handpicked for each tree to measure yield as previously reported (León et al., 2007).

\section{Aerial data acquisition and processing}

A UAV flight was carried out over the study field on 12/04/2018; it was a sunny day with low wind speed. The UAV platform was a quadcopter model MD4-1000 (microdrones $\mathrm{GmbH}$, Siegen, Germany) equipped with a Sony ILCE-6000 camera (Sony Corporation, Tokyo, Japan). The camera has a $23.5 \times 15.6 \mathrm{~mm}$ APS-C CMOS sensor with a resolution of 24 megapixels $(6000 \times 4000$ pixels $)$ and is equipped with a $20 \mathrm{~mm}$ lens. The UAV flight was carried out at noon on a cloudless day to minimize shadow effects, at an altitude of $30 \mathrm{~m}$ above-ground level, and with a grid pattern following a trajectory designed to spatially cover the entire study site with forward and side overlaps of $91 \%$ and $60 \%$, respectively. The imagery spatial resolution was $6 \mathrm{~mm}$ per pixel.

The aerial images were processed using PhotoScan Professional Edition (Agisoft LLC, St. Petersburg, Russia) version 1.2.4 for the creation of the photogrammetric point cloud. The process was fully automatic, with the only exception being the manual location of five ground control points. Coordinates of these points were registered using a real time kinematic (RTK) GNSS linked to a reference station from the GNSS network from the Institute for Statistics and Cartography of Andalusia (IECA), Spain. The accuracy of the GNSS-RTK system was about $0.02 \mathrm{~m}$ in the $\mathrm{X}-\mathrm{Y}$ axis directions and $0.03 \mathrm{~m}$ in the Z-axis direction. At the end of the process, the point cloud was stored in ".las" format, an open binary format specified by the American Society for Photogrammetry and Remote Sensing. Readers can find more information about the processing parameters in Torres-Sánchez et al (2018).

\section{OBIA algorithm}

The 3D information of the olive trees was automatically extracted from the photogrammetric point cloud using an automatic OBIA algorithm. It does not need any user intervention, and was designed using Cognition Network programming language in eCognition Developer 9.3 software (Trimble GeoSpatial, Munich, Germany). The algorithm was created for the analysis of vineyards in trellis systems (López-Granados et al., 2020), but it was adapted and re-parameterized to be applied in an olive hedgerow scenario due to the 
similarity of this orchard structure with vineyards under a trellis system. The algorithm can be divided in to the following steps, although more information can be found in LópezGranados et al (2020):

1. Digital terrain model (DTM) generation the point cloud was segmented following a $2 \times 2 \mathrm{~m}$ grid pattern. The points in each $2 \times 2 \mathrm{~m}$ square that belong to the $15 \%$ of points with lower height were assumed to belong to the soil. Their average height was calculated and stored in an image layer called "DTM". This approach has been successfully used and validated in other woody crops (de Castro et al., 2019; Torres-Sánchez et al., 2018).

2. Olive hedgerow classification a chessboard pattern was overlaid over the point cloud to split it in to $0.1 \times 0.1 \mathrm{~m}$ squares. The squares containing points with a height over the DTM greater than $1 \mathrm{~m}$ were classified as "olive". The points higher than $0.5 \mathrm{~m}$ inside the "olive area" were stored in a new point cloud.

3. Point cloud slicing the new point cloud was split in to $0.1 \mathrm{~m}$ height slices following the $\mathrm{Z}$-axis direction. As the point cloud was already divided in to $0.1 \mathrm{~m}$ squares, it follows that the olive point cloud was segmented in voxels (i.e., 3D pixels) with $0.1 \mathrm{~m}$ side. A new image layer stored the number of voxels with olive points that share $x, y$ coordinates with each one of the $0.1 \mathrm{~m}$ squares created in the first step. As the volume of the voxels was known $\left(0.1 \times 0.1 \times 0.1 \mathrm{~m}^{3}\right)$, it was possible to calculate the volume occupied by the olives in every pixel of the new layer. The slicing of the point cloud with this voxel size has been successfully used in previous research (de Castro et al., 2019; López-Granados et al., 2019).

4. Hedgerow segmentation the olive hedgerows were split in to $0.1 \mathrm{~m}$ length slices along the hedgerow direction.

5. Hedgerow segments characterization the volume of each hedgerow slice was estimated by counting the number of voxels including "olive points" that were inside the slice. For every slice, the height was the point with maximum height over the DTM. In addition, the slice projected area was derived from the classification carried out in the "olive hedgerow classification" step of the algorithm.

The hedgerow segments were grouped to isolate individual trees taking into account the planting pattern. The algorithm detected the extreme of the hedgerow and grouped the row slices every $1.5 \mathrm{~m}$. Data analysis was performed on the 3D parameters of the trees rather than the parameters of the slices. For the aggregation of the slices, the sum of the values was calculated for volume and area, while the maximum was computed for height, and width at different heights. The combination of the width of the tree slices with their height resulted in a set of rectangles depicting the transversal section of the tree (Fig. 1). The aggregation of the areas of these rectangles gave the transversal area of the tree.

\section{Data analysis}

Average transversal sections for each rootstock were created to visualise the shape differences among them. Since not all the rootstocks had the same number of trees, five trees were randomly selected for each rootstock in order to make the data more comparable. These figures were made using bar charts to represent the width of the trees at different heights. To create a representation of the tree silhouette for each rootstock (Fig. 1), the 


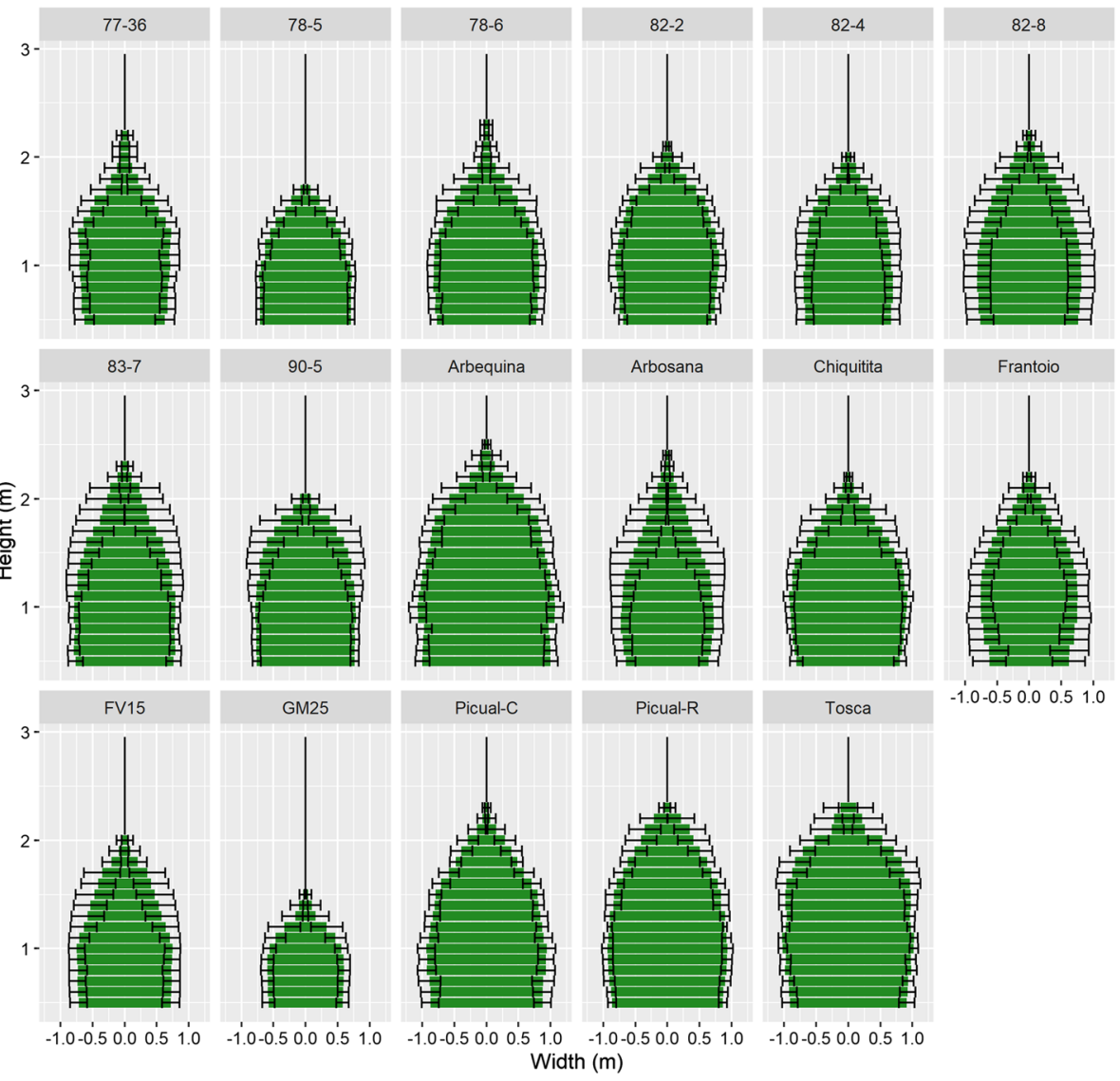

Fig. 1 Graphical representation of the average 'Picual' canopy width at different heights for the rootstocks studied, including 'Picual' self-grafted (Picual-R). 'Picual' self-rooted (Picual-C) was also included. Data from five randomly selected trees per rootstock were used. Black lines indicate the standard deviation of the width among trees of the same rootstock or cultivar

value of the width at every height slice was halved, and every half was represented in a side of the $\mathrm{x}$-axis.

The main architectural parameters (height, projected area, volume and transversal area) were subjected to analysis of variance to test the effect of rootstock. Welch's test was selected for studying this effect because volume and transversal area values did not comply with the requirement of homoscedasticity required for applying an ANOVA test. Furthermore, the correlation between yield and tree volume was studied. All the statistical analyses and charts were carried out using R software 3.5.3 (R Core Team, 2019) with the packages "ggplot2" (Wickham, 2016), "dplyr" (Wickham et al., 2019), and "userfriendlyscience" (Peters, 2018). 


\section{Results}

\section{Differences in architectural parameters among rootstocks}

The data from the analysis of the point cloud were used to fully characterize the canopy of the different 'Picual'/rootstock combinations. This allowed identification of a wide variability on the average canopy transversal section of 'Picual' between the different rootstocks, from tall and slender trees such the case where 'Arbosana' was used as rootstock, to low and stocky trees such as 'GM25 ' rootstock (Fig. 1). 'Picual' self-grafted showed a similar canopy transversal section to 'Picual' own rooted. This result suggests that some 'Picual'/rootstock combinations are more stable in their geometrical properties than others, as they have less standard deviation of the canopy transversal section measures (Fig. 1; Table 2). For example, '82-2' or '78-5 ' rootstocks showed lower standard deviation values for the width at different heights, while ' $82-8$ ' or 'Frantoio ' rootstocks presented higher standard deviation values.

An analysis of variance was applied to determine the effect of the 'Picual'/rootstock combinations on the canopy variables. Table 3 presents the results of the Welch's test for height, projected area, volume and transversal area. The analysis was applied to the UAV and the field data, except for transversal area that was not estimated from field data. The kind of 'Picual'/rootstock combination significantly affected all the studied geometric variables, regardless of whether the data came from UAV estimations or from field measured data. This confirms in a quantitative way what was inferred from Fig. 1 for height and width. The fact that UAV and field data gave similar ANOVA statistics seems to indicate a high correlation among them. This correlation was confirmed by the calculation of the

Table 2 Average of the standard deviation values of the'Picual' canopy width when grafted on to different rootstocks, including 'Picual' self-grafted (Picual-R). 'Picual' self-rooted (Picual-C) was also included

\begin{tabular}{ll}
\hline Rootstock & $\begin{array}{l}\text { Average width } \\
\text { standard devia- } \\
\text { tion }\end{array}$ \\
\hline $78-5$ & 0.19 \\
$82-2$ & 0.23 \\
Picual-R & 0.24 \\
Sikitita & 0.25 \\
GM25 & 0.25 \\
Picual-C & 0.25 \\
$78-6$ & 0.27 \\
Arbequina & 0.29 \\
$77-36$ & 0.30 \\
$82-4$ & 0.30 \\
Tosca & 0.31 \\
$90-5$ & 0.32 \\
FV15 & 0.36 \\
$83-7$ & 0.38 \\
Arbosana & 0.40 \\
Frantoio & 0.40 \\
$82-8$ & 0.42 \\
\hline
\end{tabular}


Table 3 Results for the Welch's tests on the estimated and measured variables among 'Picual'/rootstock combinations. "Df num" and "Df den" refer to the degrees of freedom of numerator and denominator, respectively

\begin{tabular}{lllll}
\hline & Height $(\mathrm{m})$ & Projected area $\left(\mathrm{m}^{2}\right)$ & Volume $\left(\mathrm{m}^{3}\right)$ & Transversal area $\left(\mathrm{m}^{2}\right)$ \\
\hline UAV data & & & & \\
F ratio & 14.10 & 8.45 & 15.99 & 14.39 \\
Df num & 16 & 16 & 16 & 16 \\
Df den & 48.75 & 48.02 & 48.33 & 48.52 \\
Prob $>$ F & $\mathrm{p}<0.001$ & $\mathrm{p}<0.001$ & $\mathrm{p}<0.001$ & $\mathrm{p}<0.001$ \\
Field data & & & & \\
F ratio & 9.84 & 6.79 & 11.74 & - \\
Df num & 16 & 16 & 16 & - \\
Df den & 47.97 & 49.84 & 50.34 & - \\
Prob $>\mathrm{F}$ & $\mathrm{p}<0.001$ & $\mathrm{p}<0.001$ & $\mathrm{p}<0.001$ & - \\
\hline
\end{tabular}

Spearman correlation coefficient, that was equal or higher than $0.79(\mathrm{p}<0.001)$ for height, projected area and volume.

The UAV derived variables analysed through the Welch's test are represented in Fig. 2 for a clearer vision of the influence of the 'Picual'/rootstock combination on the development of the olive trees. The 'Picual' canopy geometric variables measured greatly varied among the rootstock evaluated. Wild olive GM25 reduced the 'Picual' canopy more than the rest of the genotypes. Rootstocks 78-5, 82-2, 82-4, coming from 'Sikitita' x 'Arbosana' breeding cross, and the other wild FV15 also gave lower values for the canopy variables than 'Picual' self-rooted (Picual-C). Other rootstocks showed high variability among the replicates evaluated, especially cultivars 'Frantoio' and, to a lesser extent, 'Arbosana'.

\section{Tree volume and yield}

The correlation between tree volume and yield was assessed using the mean values per rootstock-scion combination. 'GM25 ' was removed from the dataset since it was not productive. With the remaining data, tree volume and yield were found to be significantly correlated, with a Pearson correlation coefficient $r(14)=0.71, p<0.01,95 \%$ CI $[0.33,0.89]$. Figure 3 is a graphical representation of the comparison between yield and UAV estimated tree volume. It can be seen that there were differences among genotypes; e.g., 'Tosca' and 'Arbequina' were the only two rootstocks promoting higher canopy volume and yield in 'Picual' relative to this cultivar on its own roots. Rootstock '78-5 ' seems to be interesting as promoting a very low canopy volume in 'Picual' with only a small decrease in yield. The wild 'FV15' was the rootstock with less volume and yield.

\section{Discussion}

The rootstocks here used to graft 'Picual' cultivars produced a wide variability in canopy volume and transversal section. This variability included several genotypes which conferred a lower canopy volume to 'Picual' than the cultivar grown on its own roots. 

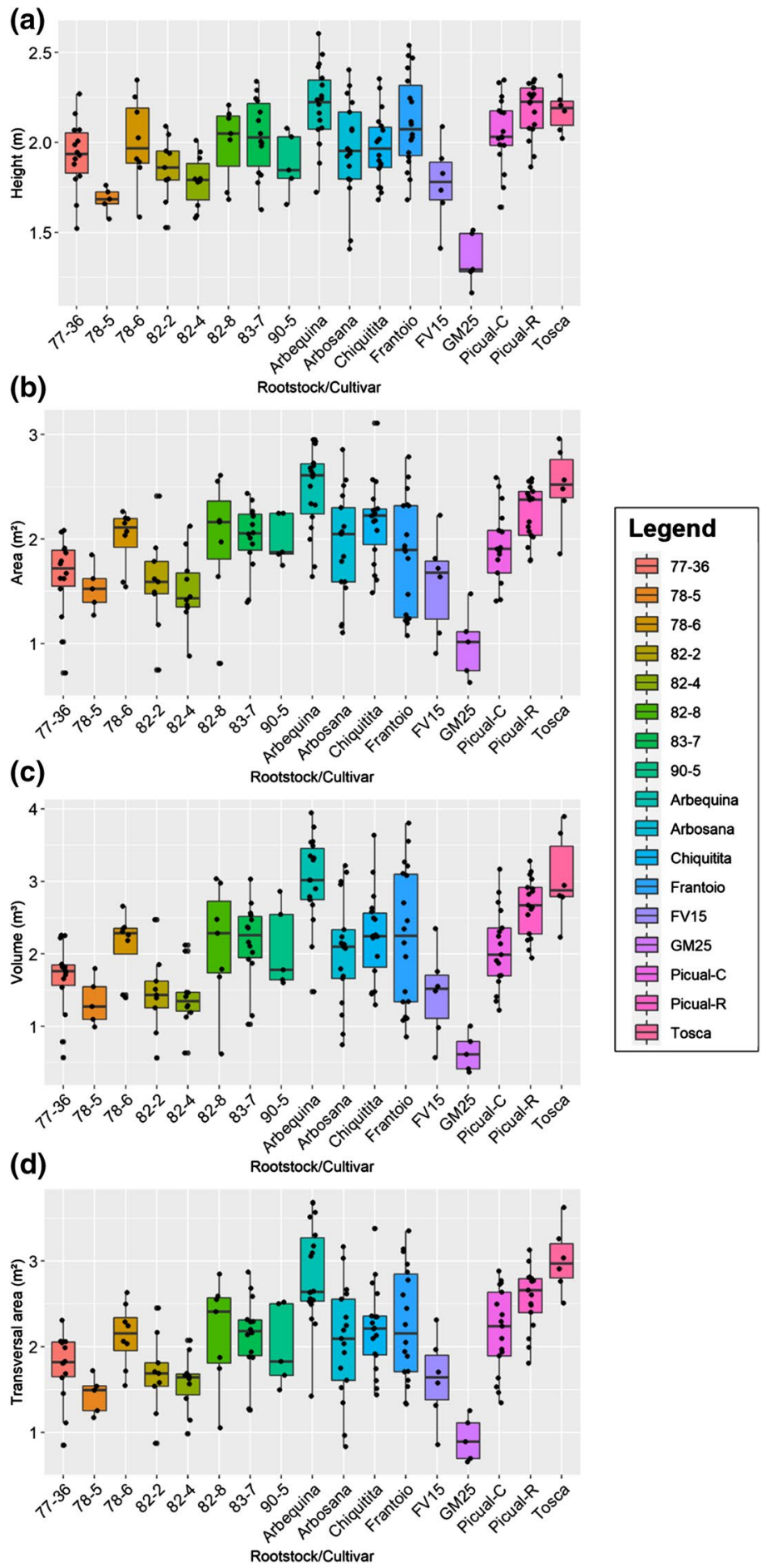

Fig. 2 Boxplots comparing the variables studied from UAV data among rootstocks and cultivars: a height, b projected area, c volume, $\mathbf{d}$ transversal area 


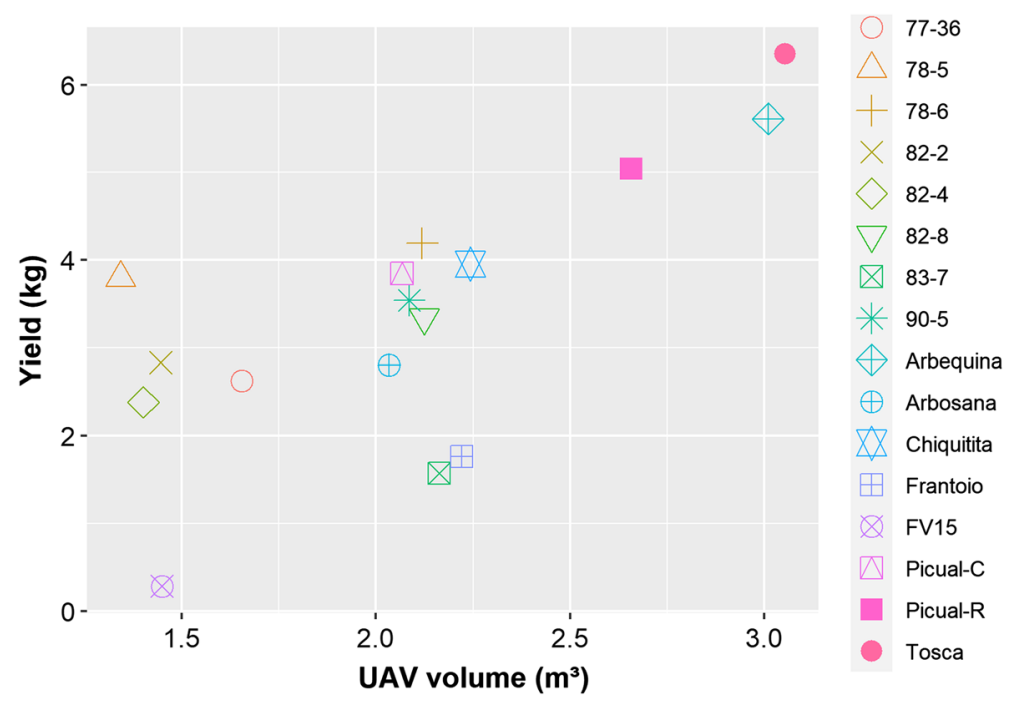

Fig. 3 Graphical comparison of UAV estimated volume and yield using the mean values per rootstock-scion combination

This is the case of some of the seedlings of the 'Sikitita' $\times$ 'Arbosana' cross and also the two wild genotypes used in the present study. It is worth noticing that low vigour cultivars such as 'Tosca' (Abenoza et al., 2014) or 'Arbequina' (De la Rosa et al., 2007) produced a high canopy volume in 'Picual' while 'Frantoio', a high vigour cultivar (León et al., 2007), produced a vigour canopy volume in 'Picual' similar to that cultivar grown on its own roots. This fact suggests that there is not a direct relationship between the vigour of the cultivar and its dwarfing effect. This effect of the rootstock on the scion might be caused by a reduction in root hydraulic conductance (Nardini et al., 2006). This means that the dwarfing rootstock has a higher resistance to water flow in roots which causes a reduction of the total leaf surface area of the scion. Another mechanism that could partly explain the dwarfing effect is that the rootstocks might be affecting the expression of genes related to canopy growth of the scion. This has been described for apple vigour where MdFT genes of M.9 rootstock seems to promote earlier shoot termination (reduction in growth) in the scion as a part of the rootstock dwarfing effect (Foster et al., 2014).

Previous works on olive have also evaluated the dwarfing effect of 'Leccino Dwarf', and genetic variability of this character in olive has been previously reported in 'Arbequina' olive in vase formation when grafted with 18 olive cultivars (Di Vaio et al., 2012; Romero et al., 2014). In relation to canopy dimensions, high variability of tree height and canopy spread due to different rootstocks has been found for'Fuji' and'McIntosh' apple cultivars (Autio et al., 2011) and cherry (Blažková et al., 2020).

The evaluation of the genetic variability has allowed identification of a high correlation between canopy volume and first harvest, which could be related with earliness of bearing that the different rootstocks produce on the 'Picual' cultivar. Therefore, the yield/volume ratio was more or less constant for most of the rootstocks evaluated, for the first harvest here evaluated. A positive correlation between vigour and yield has also been found when using dwarfing rootstocks in apple (Costes et al., 2006). This could be explained by the 
positive correlation between light interception and yield response previously reported for olive (Gómez-del-Campo et al., 2020); although this should be confirmed with further experiments with more years of crop evaluation. However, some genotypes showed a much lower yield/volume ratio than the general ratio, such as '83-7' and 'Frantoio'. From the two wild genotypes evaluated,'FV15' also showed a very low yield/volume ratio, while the other wild genotype did not show any yield at all. This could be due to problems associated with graft compatibility as widely reported in other fruit crops usually propagated by grafting, such as the case of almond (Rubio-Cabetas et al., 2017). On the other hand,'78-5' seedling showed a high yield with respect to the canopy volume. Other genotypes such as' 82-4','82-2' and'77-36' seem also to reduce canopy volume, keeping a yield in first harvest comparable to 'Picual' when self-rooted.

Another interesting parameter to be considered is the homogeneity of the canopy traits measured among trees grafted with the same rootstock. Interestingly, the above mentioned seedlings which had low vigour and high yield ('78-5', 82-2', 82-4' and'77-36') also showed a reduced variance among trees. In contrast, most of the cultivars used showed a high variance for the canopy parameters evaluated. It is worth mentioning that a homogeneous hedgerow is a desirable trait to facilitate access to straddle machinery for harvesting, pruning and phytosanitary treatments and even for fertigation (Connor et al., 2014; Fernández-Escobar et al., 2013).

However, it has to be taken into account that this is an early work on the initial variability of the dwarfing effect of different olive rootstocks on 'Picual'. Before any genotype can be considered as having a consistent dwarfing effect and a satisfactory productivity, more work is needed to confirm the promising dwarfing effect of'78-5', 82-2', '82-4' and'77-36' rootstocks and including a wider number of replicates per rootstock. Especially, as previously mentioned, the variability among replicates of the same rootstock is of paramount importance given the necessity of having a homogeneous hedgerow for easier management of mechanized operations (Fernández-Escobar et al., 2013). This, together with other rootstocks such as 'Tosca' or 'Arbequina', seem to promote high vigour in 'Picual', while others might be producing a decrease in fruit yield such as the two wilds 'GM25' and 'FV15'. Additionally, it should be tested in further field experiments whether the dwarfing effect is similar in different cultivars used as scion or if there would be a scion/rootstock interaction as reported for other fruit species (Tworkoski \& Miller, 2007). In these planned experiments, it will be tested whether the dwarfing effect on traditional cultivars is enough for long-term viability of high density orchards. Other parameters such as branching habit (Rosati et al., 2013) and branch flexibility should be also evaluated as they could limit the ability of a dwarfed traditional cultivar from being mechanically managed in hedgerow orchards.

The use of UAV-RGB technology together with the workflow developed has shown to be of great help as it can timely characterize, in a high throughput way, the olive tree vigour and volume by the analysis of photogrammetric point clouds for evaluating the dwarfing effect between the different rootstocks used on 'Picual' cultivar. Guijun et al (2017) reviewed the use of UAV imagery for crop phenotyping. They mentioned that $88.5 \%$ of the surveyed references focused on field phenotyping using UAV were published in the last 5 years, and they also discussed the opportunities for wider applications. As an example of these other applications, the present work has been centred on the phenotyping of the dwarfing effect of some rootstocks rather than in the use of the UAV photogrammetry for olive phenotyping in breeding experiments as thoroughly studied and validated in previous work (León et al., 2017; López-Granados et al., 2019; Rallo et al., 2020). 
The high degree of correlation achieved in the comparison between UAV-derived geometric traits and on-ground measurements has shown the suitability of procedures herein presented which contribute to alleviate the traditional intensive field work carried out in breeding experiments. That could improve the bottleneck of characterizing phenotypic variation of individual olive crowns in high-density olive orchards in an efficient, non-destructive and inexpensive way, and overcoming the potential effects of overlapping crowns of neighbouring olives. Another of the main advantages of this workflow in comparison with on-ground laborious approaches is the ability to generate a large amount of useful on time not only for mapping geometric tree features but also for digitizing and precision management applications allowing the optimized application of agronomic tasks such as pruning, fertilization, irrigation or pesticide use. For example, this $3 \mathrm{D}$ information can be potentially used as a baseline tool for the design of site-specific tree management according to the tree location and crown architecture in the case that negative canopy circumstance occurs during the breeding program, e.g., a fungal foliar disease. As previously mentioned, the technology presented here could generate economic and environmental benefits in the context of breeding programs and precision agriculture.

\section{Conclusions}

In summary, the wide variability observed in the different rootstocks evaluated for the vigour that they transmit to 'Picual' as scion indicates that selection for dwarfing rootstocks is a motivating topic for olive breeding that could enlarge the limited number of cultivars suitable for high-density growing systems. For that matter, as mentioned above, further experiments with breeding selections'78-5,'82-2,'82-4' and'77-36' should be done with a higher number of replicates and more traditional cultivars as scions. The use of UAV technology to evaluate canopy vigour and its variability is a cost-effective and more accurate alternative to on-ground measurements and therefore could improve the rootstock selection process. The results herein presented also have special interest due to both reducing the time for field characterization of olive traits, increasing the whole efficiency in human resources and duration of the selection processes. In addition, the use of dwarfing rootstocks would improve the availability of frequently required cultivars from breeders and emerging super-high density olive companies.

Acknowledgements This research was financed by the PID2020-113229RB-C44 (Spanish Ministry of Science \& Innovation-ERDF: European Regional Development Fund), AVA2016.01.2 and AVA2019.027 partially funded by ERDF, and Intramural-CSIC 202040E230 projects.

Funding Open Access funding provided thanks to the CRUE-CSIC agreement with Springer Nature.

Open Access This article is licensed under a Creative Commons Attribution 4.0 International License, which permits use, sharing, adaptation, distribution and reproduction in any medium or format, as long as you give appropriate credit to the original author(s) and the source, provide a link to the Creative Commons licence, and indicate if changes were made. The images or other third party material in this article are included in the article's Creative Commons licence, unless indicated otherwise in a credit line to the material. If material is not included in the article's Creative Commons licence and your intended use is not permitted by statutory regulation or exceeds the permitted use, you will need to obtain permission directly from the copyright holder. To view a copy of this licence, visit http://creativecommons.org/licenses/by/4.0/. 


\section{References}

Abenoza, M., Benito, M., Oria, R., \& Sánchez-Gimeno, A. C. (2014). Quality characterization of the olive oil from Var. Tosca $07 \AA$ grown in a commercial high density orchard. Journal of the American Oil Chemists' Society, 91(4), 613-622. https://doi.org/10.1007/s11746-013-2408-8

Autio, W. R., Robinson, T. L., Black, B., Bradshaw, T., Cline, J. A., Crassweller, R. M., Embree, C. G., Hoover, E. E., Hoying, S. A., Iungerman, K. A., \& Johnson, R. S. (2011). Performance of 'Fuji' and 'McIntosh' apple trees after 10 years as affected by several Semidwarf rootstocks in the 1999 NC-140 Apple Rootstock Trial. Journal of the American Pomological Society, 65(2), 21.

Barranco, D., Cimato, A., Fiorino, P., Rallo, L., Touzani, A., Castañeda, C., Serafín, F., \& Trujillo, I. (2000). World catalogue of olive varieties. International Olive Oil Council.

Barranco, D., \& Rallo, L. (2000). Olive cultivars in Spain. HortTechnology, 10(1), 107-110. https://doi.org/ 10.21273/HORTTECH.10.1.107

Blažková, J., Skřivanová, A., Suran, P., Zelený, L., \& Paprštein, F. (2020). Long-term evaluation of rootstock effects on cropping and tree parameters of selected sweet cherry cultivars. Horticultural Science, 47(1), 13-20. https://doi.org/10.17221/39/2018-HORTSCI

Centeno, A., Hueso, A., \& Gómez-del-Campo, M. (2019). Long-term evaluation of growth and production of olive cultivars in super high-density orchard under cold-weather conditions. Scientia Horticulturae, 257, 108657. https://doi.org/10.1016/j.scienta.2019.108657

Connor, D. J., Gómez-del-Campo, M., Rousseaux, M. C., \& Searles, P. S. (2014). Structure, management and productivity of hedgerow olive orchards: A review. Scientia Horticulturae, 169, 71-93. https://doi. org/10.1016/j.scienta.2014.02.010

Costes, E., Lauri, P. É., \& Regnard, J. L. (2006). Analyzing fruit tree architecture: Implications for tree management and fruit production. In J. Janick (Ed.), Horticultural reviews (pp. 1-61). Wiley.

de Castro, A. I., Rallo, P., Suárez, M. P., Torres-Sánchez, J., Casanova, L., Jiménez-Brenes, F. M., Morales-Sillero, A., Jiménez, M. R., \& López-Granados, F. (2019). High-throughput system for the early quantification of major architectural traits in olive breeding trials using UAV images and OBIA techniques. Frontiers in Plant Science. https://doi.org/10.3389/fpls.2019.01472

De la Rosa, R., Leon, L., Guerrero, N., Rallo, L., \& Barranco, D. (2007). Preliminary results of an olive cultivar trial at high density. Australian Journal of Agricultural Research, 58(5), 392-395. https:// doi.org/10.1071/ar06265

Di Vaio, C., Marra, F. P., Scaglione, G., La Mantia, M., \& Caruso, T. (2012). The effect of different vigour olive clones on growth, dry matter partitioning and gas exchange under water deficit. Scientia Horticulturae, 134, 72-78. https://doi.org/10.1016/j.scienta.2011.11.001

Díaz-Rueda, P., Franco-Navarro, J. D., Messora, R., Espartero, J., Rivero-Núñez, C. M., Aleza, P., Capote, N., Cantos, M., García-Fernández, J. L., de Cires, A., \& Belaj, A. (2020). SILVOLIVE, a Germplasm collection of wild subspecies with high genetic variability as a source of rootstocks and resistance genes for olive breeding. Frontiers in Plant Science. https://doi.org/10.3389/fpls.2020. 00629

FAOSTAT. (2021). Retrieved April 19, 2021 from http://www.fao.org/faostat/en/\#data/QC

Fernández-Escobar, R., Gil-Ribes, J. A., Quesada-Moraga, E., Trapero, A., \& Msallem, M. (2013). Evolution and sustainability of the olive production systems. Options Mediterraneennes, 106, 11-42.

Foster, T. M., Watson, A. E., van Hooijdonk, B. M., \& Schaffer, R. J. (2014). Key flowering genes including FT-like genes are upregulated in the vasculature of apple dwarfing rootstocks. Tree Genetics \& Genomes, 10(1), 189-202.

Gómez-del-Campo, M., Trentacoste, E. R., \& Connor, D. J. (2020). Long-term effects of row spacing on radiation interception, fruit characteristics and production of hedgerow olive orchard (cv. Arbequina). Scientia Horticulturae, 272, 109583. https://doi.org/10.1016/j.scienta.2020.109583

Guijun, Y., Liu, J., Zhao, C., Li, Z., Huang, Y., Yu, H., Xu, B., Yang, X., Zhu, D., Zhang, X., \& Zhang, R. (2017). Unmanned aerial vehicle remote sensing for field-based crop phenotyping: Current status and perspectives. Frontiers in Plant Science, 8, 1111. https://doi.org/10.3389/fpls.2017.01111

Herrmann, I., Bdolach, E., Montekyo, Y., Rachmilevitch, S., Townsend, P. A., \& Karnieli, A. (2020). Assessment of maize yield and phenology by drone-mounted superspectral camera. Precision Agriculture, 21(1), 51-76. https://doi.org/10.1007/s11119-019-09659-5

Jiménez-Fernández, D., Trapero-Casas, J. L., Landa, B. B., Navas-Cortés, J. A., Bubici, G., Cirulli, M., \& Jiménez-Díaz, R. M. (2016). Characterization of resistance against the olive-defoliating Verticillium dahliae pathotype in selected clones of wild olive. Plant Pathology, 65(8), 1279-1291. https:// doi.org/10.1111/ppa.12516

Kawamura, K., Asai, H., Yasuda, T., Khanthavong, P., Soisouvanh, P., \& Phongchanmixay, S. (2020). Field phenotyping of plant height in an upland rice field in Laos using low-cost small unmanned 
aerial vehicles (UAVs). Plant Production Science, 23(4), 452-465. https://doi.org/10.1080/13439 43X.2020.1766362

Lavee, S., Avidan, B., \& Meni, Y. (2003). "Askal”, una nueva variedad de almazara sobresaliente por su comportamiento agronómico para olivares intensivos y superintensivos. ("Askal”, a new olive oil mill variety with outstanding agronomic performance for intensive and super-intensive olive groves). Olivae, 97, 53-59.

León, L., Beltrán, G., Aguilera, M. P., Rallo, L., Barranco, D., \& de la Rosa, R. (2011). Oil composition of advanced selections from an olive breeding program. European Journal of Lipid Science and Technology, 113(7), 870-875. https://doi.org/10.1002/ejlt.201000535

León, L., de la Rosa, R., Barranco, D., \& Rallo, L. (2007). Breeding for early bearing in olive. HortScience, 42(3), 499-502. https://doi.org/10.21273/HORTSCI.42.3.499

León, L., Díaz-Varela, R. A., Zarco-Tejada, P. J., \& de la Rosa, R. (2017). Tree crown parameters assessment using $3 \mathrm{D}$ photo reconstruction as a tool for selection in olive breeding programs. Acta Horticulturae, 1160, 1-4. https://doi.org/10.17660/ActaHortic.2017.1160.1

López-Granados, F., Torres-Sánchez, J., Jiménez-Brenes, F. M., Arquero, O., Lovera, M., \& de Castro, A. I. (2019). An efficient RGB-UAV-based platform for field almond tree phenotyping: 3-D architecture and flowering traits. Plant Methods, 15(1), 160. https://doi.org/10.1186/s13007-019-0547-0

López-Granados, F., Torres-Sánchez, J., Jiménez-Brenes, F. M., Oneka, O., Marín, D., Loidi, M., de Castro, A. I., \& Santesteban, L. G. (2020). Monitoring vineyard canopy management operations using UAV-acquired photogrammetric point clouds. Remote Sensing, 12(14), 2331. https://doi.org/ $10.3390 /$ rs 12142331

Lordan, J., Francescatto, P., Dominguez, L. I., \& Robinson, T. L. (2018). Long-term effects of tree density and tree shape on apple orchard performance, a 20 year study-Part 1, agronomic analysis. Scientia Horticulturae, 238, 303-317. https://doi.org/10.1016/j.scienta.2018.04.033

Marino, G., Macaluso, L., Marra, F. P., Ferguson, L., Marchese, A., Campisi, G., Volo, P., Laudicina, V. A., \& Caruso, T. (2017). Horticultural performance of 23 Sicilian olive genotypes in hedgerow systems: Vegetative growth, productive potential and oil quality. Scientia Horticulturae, 217, 217-225. https://doi.org/10.1016/j.scienta.2017.01.046

Nardini, A., Gascó, A., Raimondo, F., Gortan, E., Lo Gullo, M. A., Caruso, T., \& Salleo, S. (2006). Is rootstock-induced dwarfing in olive an effect of reduced plant hydraulic efficiency? Tree Physiology, 26(9), 1137-1144. https://doi.org/10.1093/treephys/26.9.1137

Navas-López, J. F., Cano, J., de la Rosa, R., Velasco, L., \& León, L. (2020). Genotype by environment interaction for oil quality components in olive tree. European Journal of Agronomy, 119, 126115. https://doi.org/10.1016/j.eja.2020.126115

Navas-López, J. F., León, L., Trentacoste, E. R., \& de la Rosa, R. (2019). Multi-environment evaluation of oil accumulation pattern parameters in olive. Plant Physiology and Biochemistry, 139, 485-494. https://doi.org/10.1016/j.plaphy.2019.04.016

Paulus, S. (2019). Measuring crops in 3D: Using geometry for plant phenotyping. Plant Methods, 15(1), 103. https://doi.org/10.1186/s13007-019-0490-0

Pérez-López, D., Ribas, F., Moriana, A., Rapoport, H. F., \& Juan, A. D. (2008). Influence of temperature on the growth and development of olive (Olea europaea L.) trees. The Journal of Horticultural Science and Biotechnology, 83(2), 171-176. https://doi.org/10.1080/14620316.2008.11512366

Perez-Sanz, F., Navarro, P. J., \& Egea-Cortines, M. (2017). Plant phenomics: An overview of image acquisition technologies and image data analysis algorithms. GigaScience, 6(11), 1-18. https://doi. org/10.1093/gigascience/gix092

Peters, G. (2018). userfriendlyscience: Quantitative analysis made accessible (0.7.2) [Computer software]. Retrieved October 14, 2020 from https://userfriendlyscience.com

R Core Team. (2019). R: A language and environment for statistical computing (3.5.3) [Computer software]. Retrieved from https://www.R-project.org/

Rallo, L., Barranco, D., De La Rosa, R., \& Leon, L. (2008). 'Chiquitita' olive. HortScience, 43(2), 529-531.

Rallo, P., de Castro, A. I., López-Granados, F., Morales-Sillero, A., Torres-Sánchez, J., Jiménez, M. R., Casanova, L., \& Suárez, M. P. (2020). Exploring UAV-imagery to support genotype selection in olive breeding programs. Scientia Horticulturae, 273, 109615. https://doi.org/10.1016/j.scienta. 2020.109615

Romero, A., Hermoso, J. F., \& Tous, J. (2014). Olive rootstocks to control "Arbequina IRTA-I18” clone vigour-Results from a second one comparative trial. Acta Horticulturae, 1057, 577-584.

Rosati, A., Paoletti, A., Caporali, S., \& Perri, E. (2013). The role of tree architecture in super high density olive orchards. Scientia Horticulturae, 161, 24-29. https://doi.org/10.1016/j.scienta.2013.06. 044 
Rubio-Cabetas, M. J., Felipe, A. J., \& Reighard, G. L. (2017). Rootstock development. In R. Socias i Company \& T. M. Gradziel (Eds.), Almonds: Botany, production and uses (pp. 209-227). CABI.

Rugini, E., \& Pace, C. D. (2016). Olive breeding with classical and modern approaches. In E. Rugini (Ed.), The olive tree genome (pp. 163-193). Springer.

Torres, M., Pierantozzi, P., Searles, P., Rousseaux, M. C., García-Inza, G., Miserere, A., Bodoira, R., Contreras, C., \& Maestri, D. (2017). Olive cultivation in the southern hemisphere: Flowering, water requirements and oil quality responses to new crop environments. Frontiers in Plant Science. https://doi.org/10.3389/fpls.2017.01830

Torres-Sánchez, J., de Castro, A. I., Pena, J. M., Jimenez-Brenes, F. M., Arquero, O., Lovera, M., \& Lopez-Granados, F. (2018). Mapping the 3D structure of almond trees using UAV acquired photogrammetric point clouds and object-based image analysis. Biosystems Engineering, 176, 172-184. https://doi.org/10.1016/j.biosystemseng.2018.10.018

Tworkoski, T., \& Miller, S. (2007). Rootstock effect on growth of apple scions with different growth habits. Scientia Horticulturae, 111(4), 335-343. https://doi.org/10.1016/j.scienta.2006.10.034

University of Jaén. (2020). Variedad: PICUAL. Retrieved December 11, 2020 from http://www.ujaen.es/ huesped/aceite/variedades/picual.htm

Vyvyan, M. C. (1955). Interrelation of scion and rootstock in fruit-trees: I. Weights and relative weights of young trees formed by the reciprocal unions, as scion and rootstock, of three apple rootstock varieties: M. IX, M. IV, and M. XII. Annals of Botany, 19(3), 401-423.

Warschefsky, E. J., Klein, L. L., Frank, M. H., Chitwood, D. H., Londo, J. P., von Wettberg, E. J. B., \& Miller, A. J. (2016). Rootstocks: Diversity, domestication, and impacts on shoot phenotypes. Trends in Plant Science, 21(5), 418-437. https://doi.org/10.1016/j.tplants.2015.11.008

Watanabe, K., Guo, W., Arai, K., Takanashi, H., Kajiya-Kanegae, H., Kobayashi, M., Yano, K., Tokunaga, T., Fujiwara, T., Tsutsumi, N., \& Iwata, H. (2017). High-throughput phenotyping of sorghum plant height using an unmanned aerial vehicle and its application to genomic prediction modeling. Frontiers in Plant Science. https://doi.org/10.3389/fpls.2017.00421

Wickham, H. (2016). ggplot2: Elegant Graphics for Data Analysis (3.3.3) [Computer software]. Retrieved October 14, 2020 from https://ggplot2.tidyverse.org

Wickham, H., François, R., Henry, L., \& Müller, K. (2019). dplyr: A grammar of data manipulation (0.8.3) [Computer software]. Retrieved October 14, 2020 from https://CRAN.R-project.org/package=dplyr

Publisher's Note Springer Nature remains neutral with regard to jurisdictional claims in published maps and institutional affiliations. 